Association for Information Systems AIS Electronic Library (AISeL)

PACIS 2003 Proceedings

Pacific Asia Conference on Information Systems

(PACIS)

December 2003

\title{
Improving New Product Quality: An Empirical Study of Product Development Teams in Taiwan
}

Tsang-Jung Chang

National Sun Yat-Sen University

Gary Hu

National Sun Yat-Sen University

Louis White

University of Houston Clear Lake

Follow this and additional works at: http://aisel.aisnet.org/pacis2003

\section{Recommended Citation}

Chang, Tsang-Jung; Hu, Gary; and White, Louis, "Improving New Product Quality: An Empirical Study of Product Development Teams in Taiwan" (2003). PACIS 2003 Proceedings. 83.

http://aisel.aisnet.org/pacis2003/83

This material is brought to you by the Pacific Asia Conference on Information Systems (PACIS) at AIS Electronic Library (AISeL). It has been accepted for inclusion in PACIS 2003 Proceedings by an authorized administrator of AIS Electronic Library (AISeL). For more information, please contact elibrary@aisnet.org. 


\title{
Improving New Product Quality: An Empirical Study of Product Development Teams in Taiwan
}

\author{
Tsang-Jung Chang ${ }^{\mathrm{a}}$, G.. Gary Hu ${ }^{\mathrm{b}}$ and Louis P. White ${ }^{\mathrm{c}}$ \\ ${ }^{a}$ Department of Business Management, National Sun Yat-sen University \\ 70, Lien-hai Rd., Kaohsiung, Taiwan, R.O.C., 804 \\ d8841804@student.nsysu.edu.tw \\ ${ }^{\mathrm{b}}$ Department of Business Management, National Sun Yat-sen University \\ 70, Lien-hai Rd., Kaohsiung, Taiwan, R.O.C., 804 \\ ghu@cm.nsysu.edu.tw \\ ${ }^{c}$ Department of Business Management, University of Houston-Clear Lake \\ 2700, Bay Area Blvd., Houston, Texas, U.S.A., 77058 \\ whitel@cl.uh.edu
}

\begin{abstract}
The role of team and organizational factors affecting new product quality and their interactions as moderating the effects are examined. Results from a domestic study suggest that new product quality is positively affected by information capability in the team and quality orientation in the firm; in contrast, it is negatively related to the innovativeness of the new product as seen by the firm and speed-to-market pressure in the team. However, teams' information capabilities alleviate the negative effect of innovativeness on quality. Quality orientation lessens the relationship between information capability and new product quality. Functional diversity and tenure diversity do not affect new product quality. In addition, managerial implications and directions for future research are proposed.
\end{abstract}

\section{Keywords}

New product development teams, cross-functional teams, new product quality, new product development.

\section{Introduction}

Product quality has received increasing attention in both practice and research (Menon, Jaworski \& Kohli 1997), as evidenced by the growing number of firms instituting quality programs, and the abundance of coverage in both business-oriented periodicals (Byrne 1994, Calonius 1991, Jacob 1993) and research-based academic literature (Aaker \& Jacobson 1994, Curry 1985, Fornell 1992, Phillips, Chang \& Buzzell 1983, Shetty 1987). The main reason is that product quality delivers superior customer value, which is the cornerstone of a firm's competitive advantage in the marketplace (Day \& Wensley 1988). As such, new product quality has been found to have a major influence on the market success and profitability of a new product. This concept has been widely recognized by domestic enterprises since Japanese products began capturing a major share of the market in one industry around the world since the 1980s (Bounds, Yorks, Adams \& Ranney 1994, Clark \& Fujimoto 1991, Garvin 1988). 
In order to enhance the quality of their new products, a number of firms in Taiwan have introduced different quality-improvement techniques, such as quality control circle (QCC) and total quality management (TQM) in different phases, which are believed to have helped Japanese companies improve new product quality (Bounds et al. 1994, Clark \& Fujimoto 1991). One of the five TQM interventions prescribed by Juran, Ishikawa and Deming is the use of cross-functional teams to identify and solve quality problems (Hackman \& Wageman 1995). As a result, giving the product development task to cross-functional teams is rapidly increasing. These teams are composed of individuals from a variety of functional areas, such as manufacturing, engineering, marketing, research and development, and purchasing. Crossfunctional teams are thought to better link upstream and downstream organizational activity (so that, for example, manufacturing considerations can be designed into a product rather than being discovered after prototypes already exist), to push decision making down to those who have the real expertise, and to speed coordination (Ancona, Kochan, Scully, Maanen \& Westney 1996).

Although previous studies have suggested that the diverse backgrounds of cross-functional team members can increase the amount and variety of information available to design products, thereby improving design process efficiency and product development performance (Brown \& Eisenhardt 1995, Clark \& Fujimoto 1991, Iansiti 1993, Chang, Hu \& White 2002). Few would argue however, that the mere formation of such teams is sufficient to meaningfully enhance new product quality (Bounds et al. 1994, Wheelwright \& Clark 1992, Sethi 2000). However, in spite of the critical role of quality in influencing the success of a new product and the growing popularity of cross-functional product development teams, there has been little research on how these teams affect new product quality (Menon, Jaworski \& Kohli 1997).

Over the past twenty years, research about quality has been published, but most of it is either descriptive or prescriptive in nature relying heavily on anecdotes rather than on appropriate research designs (Hackman \& Wageman 1995). There exists some recent firm-level research on the determinants of product quality (Clark \& Fujimoto 1991, Menon, Jaworski \& Kohli 1997, Morgan \& Piercy 1998, Song, Souder \& Dyer 1997, Chang, Hu \& White 2002); however, these studies have mainly concentrated on the effects of macro- or firm-level variables, such as structural and cultural factors, rather than on the influence of micro- or team-level factors on new product quality. Also, firm-level research has usually focused on aggregate outcomes; e.g., the quality of a firm's products in general, instead of on how the quality of a new product is affected by the team. The knowledge generated by these firm-level studies, though certainly useful, may not be effective in explaining variations in team-level outcomes (Sethi 2000).

Research on product development teams also provide valuable insights on the effects of teams on outcomes such as market performance of the new product, cycle time, and efficiency in developing innovations (Ancona \& Caldwell 1992, Barczak \& Wilemon 1992, Eisenhardt \& Tabrizi 1995, Thamhain 1990, Chang, Hu \& White 2002). Such insights do not directly address how teams influence a different outcome, such as new product quality. Later we address the idea that team-related factors that help one type of product outcome may not necessarily facilitate other outcomes and may even harm them.

The primary objective of this study is to explore how various aspects of cross-functional teams and organizational context enhance or diminish new product quality. On the basis of previous literature, it can be suggested that the emergence of a quality outcome can be affected by two sets of factors---the characteristics of the team and organizational context 
influences on the team. Therefore, we consider variables related to these two sets of factors. First, team characteristics are referred to as a critical team process and the physical composition of the team (the homogeneity of organization tenure and the mix of functional specialties). Second, organizational context influences on the team are regarded as the effects of the speed-to-market pressure, the innovativeness of the product, customers' involvement in the product development process, suppliers' customers' involvement on the product development process, and quality orientation of the firm.

We selected these variables for the following purposes: (1) studying the extent to which team factors affect new product quality will benefit both business practice and theory. Since these factors can be influenced by managers, the findings of the study should provide useful suggestions for increasing new product quality, thus improving the success and profitability of the new product; (2) extending the existing research on quality to the team level will make a critical contribution to theory building. Team-level research must focus more on group study rather than on concepts drawn from sociology or organizational theory, and (3) examining how clearly conflicting demands placed on new product teams influence new product quality. We focus on these effects in order to clarify possible trade-offs related to different expectations that managers have about the new product.

We begin with an overview of our proposed conceptual model and research hypotheses. Then, we describe our research design and discuss the sample, measures, and data collection procedures. After reporting the study findings, we conclude with a discussion of implications for practice and future research.

\section{Conceptual Model and Hypotheses}

Figure 1 identifies the general relationship between team characteristics, organization contextual factors, and new product quality. In particular, the model illustrates three moderating relationships: (1) the relationship between speed-to-market pressure and new product quality is moderated by the capability of information integration, (2) the relationship between product innovativeness and new product quality is moderated by the capability of information integration, and (3) the relationship between capability of information integration and new product quality is moderated by quality orientation. We first discuss the hypotheses linking team characteristics to new product quality, then organization contextual factors, and finally the moderator hypotheses. 


\section{Team Characteristics}

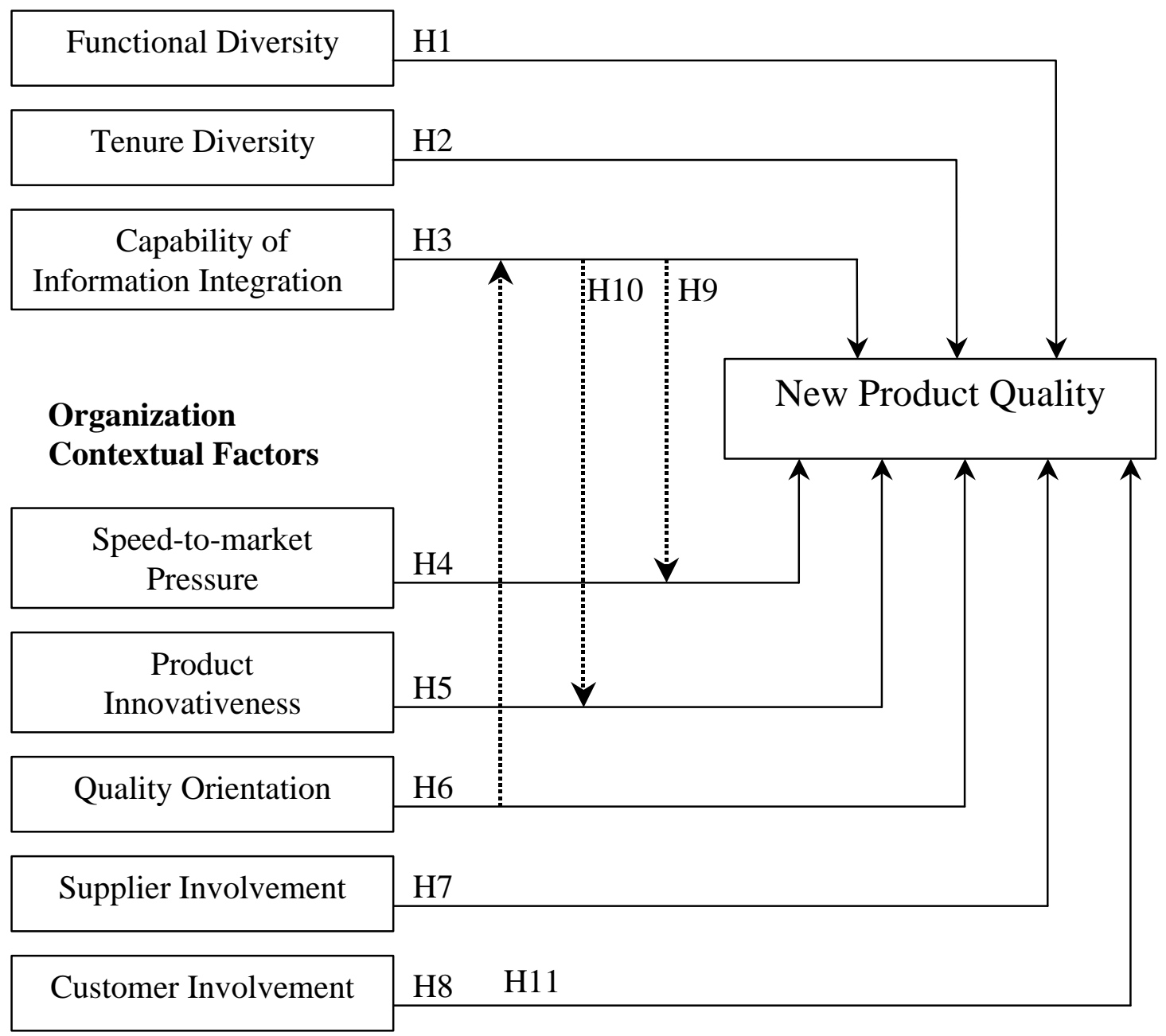

Figure 1. A model of team characteristics and organization contextual factors affecting new product quality 


\section{Team Characteristics and New Product Quality}

As mentioned earlier, we considered two important team characteristics in this study: (1) physical composition and (2) team process. As to the physical composition, we focus on functional diversity and tenure diversity, which are likely to be of particular importance for new product development teams. In the quality literature, it is considered important to include several functional areas, which can bring diverse input to the decision-making process (Bounds et al. 1994, Clark \& Fujimoto 1991, Garvin 1988). Additionally, different team tenure can provide a range of skills and perspectives to obtain higher overall performance (Ancona \& Caldwell 1992). Regarding the team process, we focus on the capability of information integration across functional areas. The capability of information integration refers to the degree to which members of the team share, pay attention to, and challenge one another's information and perspectives resulting in new insights about the product (Sethi 2000). This can be viewed as a special case of the general concept of integration, which focuses on interaction and collaboration between functional areas at the firm level (Griffin \& Hauser 1996, Gupta, Raj \& Wilemon 1986, Kahn 1996, Ruekert \& Walker 1987).

\section{Functional diversity}

We define cross-functional diversity as the number of functional areas represented on the team. The underlying reasoning is that the functional diversity of these teams increases the amount and variety information available to design products. The increased information helps team members to understand the design process more quickly and fully from a variety of perspectives, and thus it improves design process performance (Brown \& Eisenhardt, 1995). As Lutz (1994) noted, cross-functional diversity is bringing together people from upstream and downstream functional areas so that they can communicate and bring coordinated knowledge to bear on a project, and therefore, cross-functional new product development teams produce better-quality products more quickly and at lower cost. Thus,

Hypothesis 1: The more functionally diverse new product development teams are, the higher the new product quality will be.

\section{Tenure diversity}

The diversity of team members' tenure provides the new product development team with a range of experiences, information bases, biases, and contacts. Members who have entered the organization at different times know a different set of people and often have different technical skills and different perspectives on the organization's history (Brown \& Eisenhardt 1995). We postulate that this range of skills and perspectives improves the probability that a group will generate innovative solutions (Souder 1987) and have higher overall performance. Thus,

Hypothesis 2: The more tenure diverse new product development teams are, the higher the new product quality will be.

\section{Capability of information integration}

A team with a high capability of information integration is more likely to achieve a common understanding and consistency among team members across various decisions. This is because members can share information effectively, carefully attend to one another's perspectives, and freely challenge these perspectives and their underlying assumptions (Sethi 2000). Therefore, developing a common understanding about the product and achieving 
consistency among decisions made throughout the product development process is considered critical for the development of a good product (Clark \& Fujimoto 1991, Garvin 1988, Menon, Jaworski \& Kohli 1997). Thus,

Hypothesis 3: The more capability of information integration new product development teams have, the higher the new product quality will be.

\section{Organization Contextual Factors and New Product Quality}

In addition to the team characteristics discussed previously, the ability of a team to produce a high-quality outcome can also be affected by organization contextual influences on the team (Bounds et al. 1994). We therefore, focused on the effect of these influences to facilitate an understanding of how various contextual factors affect new product quality. The five contextual factors we consider in this study are (1) speed-to-market pressure, (2) product innovativeness from the perspective of the firm, (3) quality orientation in the firm, (4) customers' involvement, and (5) customers' involvement.

\section{Speed-to-market pressure}

Karau and Kelly (1992) suggest that a minimum level of time pressure is useful in spurring individuals to strive for a superior outcome. However, beyond a certain point, individuals are less likely to search for additional information and are expected to do restricted processing of available information, because time pressure creates a need for cognitive closure. It is especially evident when the team members strongly perceive time demands with respect to the product to be marketed. Under speed-to-market time pressure, team members may be forced to consider a narrow range of decision alternatives and may not be able to think deeply about the various ways to build superiority into the product (Karau \& Kelly 1992). Thus,

Hypothesis 4: Beyond a moderate level, speed-to-market pressure has a negative effect on new product quality.

\section{Product innovativeness}

If a new product is novel for a firm, it can hinder the emergence of a quality outcome. A very innovative product can require major changes in the existing technology and manufacturing process and thereby disturb the balance among the product, technology, and manufacturing systems (Clark \& Fujimoto 1991). However, such a balance helps the firm improve quality by bringing the variation in production under control. Since team members who work on a novel product are likely to be overwhelmed with a large diversity of unfamiliar issues, they may not have the necessary frame of mind and the time to work in a focused manner on the process of continuous improvement while at the same time balancing the demands of a new technology and the manufacturing process (Imai 1986). As a result, high product innovativeness can lead to a higher variation in production or lower product quality. Thus,

H7: The extent of supplier involvement in the product development processes positively related to new product quality.

\section{Customer involvement}

Customer involvement also has been shown to improve the effectiveness of the product concept (Cooper \& Kleinschmidt 1987, Zirger \& Maidique 1990). Hence, it is important to expose members of the product development team to customer needs and the consumption context (Bounds et al. 1994, Clark \& Fujimoto 1991, Hauser \& Clausing 1988). Moreover, it 
is useful to seek customer feedback about the team's ideas and plans (e.g., the product concept). This feedback serves as a reality check and ensures that the superiority the team has incorporated into the product is considered meaningful by customers (Sethi 2000). Thus,

H8: The extent of customer involvement on product development processes positively related to new product quality.

\section{Moderators}

In this study, we considered two moderating variables: (1) capability of information integration and (2) quality orientation. Regarding the former, we focused on the moderating effects of speed-to-market time pressure and product innovation. Regarding the latter, we focused on the moderating effect of quality orientation.

\section{Capability of information integration as a moderator on the speed-to- market pressure and quality linkage}

When a product development team's capability of information integration increases, its members are in a better position to reduce the adverse effect of high speed-to-market time pressure on new product quality (Sethi 2000). This is because team members can communicate effectively while finding time for essential activities. This can occur even under conditions of high speed-to-market time pressure, by setting task priorities, doing parallel work on different aspects of the project, and avoiding unnecessary backtracking of the development job between functional areas because of the common understanding they develop about the project (Clark \& Fujimoto 1991, Smith \& Reinertsen 1991, Takeuchi \& Nonaka 1986). The time thus saved by a team with a high capability of information integration can be used to study carefully the input of various functional areas, search for superior ways to satisfy customer needs, and keep variation in the production of the new product to a minimum. Thus,

H9: When new product development teams' capability of information integration increases, the negative effect of speed-to-market pressure on new product quality will be reduced.

\section{Capability of information integration as a moderator on the product innovativeness and quality linkage}

A product development team in which members work in a highly integrated manner might be able to minimize the disturbance in the operational balance among the product, technology, and manufacturing processes that an innovative new product creates (Clark \& Fujimoto 1991). Therefore, team members are likely to handle a large diversity of unfamiliar issues that a highly innovative new product can produce. As such, teams with high capabilities of information integration may still be able to help control variation in production, and then reduce the negative effect of high innovativeness on quality effectively. Thus,

H10: When new product development teams' capability of information integration increases, the negative effect of product innovativeness on new product quality will be reduced. 


\section{Quality orientation as a moderator on the capability of information integration and quality linkage}

As quality orientation in a firm increases, teams with high capability of information integration are expected to produce a higher-quality product. This is because a team with high capability of information integration is likely to have a better and clearer understanding and plan for the development of a quality product, and thus is in a better position to avail of other employees' commitment to quality and the superior facilities that a firm with high-quality orientation generally has (Sethi 2000). Thus,

H11: When quality orientation in a firm increases, the positive effect of information integration on new product quality will be enhanced.

\section{Covariate}

Group research has established that group size is an important variable. It indirectly influences the potential magnitude of the coefficient of variation and may affect group process and communication (Ancona \& Caldwell 1992). Therefore, we tested the model with team size as a control variable.

\section{Research Method}

\section{Sample and Data Collection}

We selected our samples from two resources. First, the samples were drawn from the top 1000 companies (in sales revenue) listed in the Common Wealth Magazine of 2002 in Taiwan. Four hundred (400) companies were chosen from among the top 1000, including electronics, electrical, information \& communication, cleaner \& cosmetics, chemical, transportation, and metal industries. We made initial contact with the general manager of each company via e-mail requesting the company's participation in the study. A total of 49 companies agreed to participate; a $12.25 \%$ return rate. Second, fifty (50) HR managers from the Association of HR Mangers were asked to participate in our research; fourteen (14) HR managers responded (35.9\% return rate). Due to cultural differences and sensitivity of commercial secrets, most firms in Taiwan are hesitant to allow their R\&D personnel to form relations with outsiders, such as researchers and scholars. This created a problem when attempted to obtain a large sample size in the study of new product developments teams. So, while we asked 450 firms to participate in the research, only 63 companies were willing to take part. Therefore, from the 63 companies participating, 168 new product development teams were included in our sample. A of copy of the questionnaire, a personalized letter, and a return envelope were mailed to the informants.

\section{Measurement}

\section{New Product Quality}

We used the scale developed by Olson, Walker and Reukert (1995) to measure new product quality. Ten items asked team managers for their assessment of the degree to which the new product delivers value to the customer and meets the quality control standards laid out for it by the team/organization. A seven-point Likert scale $(1=$ "strongly disagree" and $7=$ " strongly agree") was used for each item. 


\section{Functional diversity}

We measured functional diversity with the diversity index recommended by Teachman (1980) and used by Ancona and Caldwell (1992) and Keller (2001):

$$
H=-\sum_{i=1}^{s} P_{i}\left(\ln P_{i}\right)
$$

Under this formula, the greater the distribution of new product development team members across different functional areas, the higher the score would be for functional diversity. Membership in a functional area was determined by company organization chart. In this formula, $H$ represents heterogeneity and $P$ is the fraction share of team members assigned to marketing, manufacturing, engineering, and so forth. The only exception occurs when an area is not represented (Ancona \& Caldwell 1992, Keller 2001, Teachman 1980). For the sample of teams, functional diversity scores ranged from 0 to 2.08 (mean $=1.18$, s.d. $=0.45)$.

\section{Tenure diversity}

Allison (1978) and Pfeffer and O'Reilly (1987) suggest that the coefficient of variation (the standard deviation divided by the mean) provides the most direct and scale in-variant measure of dispersion. Therefore, to assess the relative homogeneity of team's tenure, each team's standard deviation of tenure was divided by the team mean (Ancona \& Caldwell 1992). The mean coefficient of variation of tenure across the sample of teams was 0.51 (s.d. $=0.23$ ).

\section{Capability of information integration}

The measure used to evaluate the capability of information integration is based on the conceptualisation of integration suggested by Gupta, Raj and Wilemon (1986) and the measure of market information use suggested by Deshpand and Zaltman (1982). We used four items to measure the degree to which members of a new product development team share, pay attention to, and challenge one another's information and perspectives to discover new ideas about the product. Items for each construct were scored on a seven-point Likert scale (1 = "strongly disagree" and 7 = "strongly agree").

\section{Speed-to-market pressure}

We used three items developed by Sethi (2000) to measure speed-to-market pressure that team members experienced during the development of new product. Items for each construct were scored on a seven-point Likert scale ( $1=$ "strongly disagree" and $7=$ "strongly agree").

\section{Product innovativeness}

Four items derived from Booz, Allen and Hamilton (1982) were used to assess how novel the product was for the firm. Respondents select one of four items to indicate the perspective of their firm on product innovativeness. A score of four means that innovativeness is high and the product is novel for the firm, and vice versa.

\section{Quality orientation}

We used three items to measure quality orientation; the extent to which a firm emphasizes product quality, creates a commitment to produce a quality product among its employees, and implements total quality management. A seven-point Likert scale $(1=$ "strongly disagree" and $7=$ "strongly agree") was employed for all items. 


\section{Supplier involvement}

Three items asked informants for their assessment of supplier's involvement in the development process. Items reflected the extent to which input and feedback from suppliers was relied on in the development of the product idea/concept, the evaluation of product idea/concept, and the development of design. A seven-point Likert scale ( 1 = "a great extent" and $7=$ " not at all") was employed for all items.

\section{Customer involvement}

Three items asked informants for their assessment of customer's involvement on the development process. Items reflected the extent to which input and feedback from customers was relied on in the development of the product idea/concept, the evaluation of product idea/concept, and the development of design. A seven-point Likert scale ( 1 = "a great extent" and $7=$ " not at all") was employed for all items.

\section{Covariate}

Team size was included as a control variable because prior research has found it to be related to cohesiveness and internal communication for teams (Ancona \& Caldwell 1992, Bantel \& Jackson 1989).

\section{Analyses and Findings}

In this section, we present the results of our tests of hypotheses and discuss their substantive interpretation. In turn, we consider the effects of team and contextual factors on new product quality, and the moderator hypotheses.

\section{Analyses}

Means, standard deviations, and a correlation matrix of all variables are presented in Table 1. An examination of correlations among independent variables showed that correlations ranged from 0 to .56. To test our hypotheses, we used two regression models in which we regressed the dependent variable on (1) the direct effect predictor variables in the model, and (2) the multiplicative interaction terms plus the direct effects in model 2. We then computed the difference in the multiple squared correlation coefficient $\left(R^{2}\right)$ of the equation testing the direct effects and the equation with the interaction terms to determine whether the interaction terms exist.

As shown in Table 2, model 2, which is with the interaction terms, increased the multiple squared correlation coefficient $\left(R^{2}\right)$ by 2 percent, compared to model 1 , indicating the existence of moderating effects. This finding shows that model 2 explained more variance and was a better fit than model 1 . We therefore, used model 2 to test our hypotheses. 


\begin{tabular}{|l|l|l|l|l|l|l|l|l|l|l|l|l|}
\hline \multicolumn{1}{|c|}{ Variable } & Mean & S.d. & $\mathbf{1}$ & $\mathbf{2}$ & $\mathbf{3}$ & $\mathbf{4}$ & $\mathbf{5}$ & $\mathbf{6}$ & $\mathbf{7}$ & $\mathbf{8}$ & $\mathbf{9}$ & $\mathbf{1 0}$ \\
\hline 1. New product quality & 5.55 & 0.72 & & & & & & & & & \\
\hline 2. Functional diversity & 1.18 & 0.45 & -.07 & & & & & & & & \\
\hline 3. Tenure diversity & 0.51 & 0.23 & & -.02 & & & & & & & \\
\hline 4. Capability of & 5.80 & 0.75 & $.56^{* * *}$ & .00 & .04 & & & & & & \\
\hline information integration & & & & & & & & & & & \\
\hline 5. Speed-to-market & 4.73 & 0.66 & -.02 & .17 & .05 & .06 & & & & & \\
\hline pressure & & & & & & & & & & & \\
\hline 6. Product innovation & 2.50 & 0.87 & $-.50^{* * *}$ & $.16^{*}$ & .07 & $-.26^{* * *}$ & .06 & & & & \\
\hline 7. Quality orientation & 6.15 & 0.77 & $.40^{* * * *}$ & -.01 & -.06 & $.45^{* * * *}$ & .10 & $-.32^{*}$ & & & \\
\hline 8. Supplier involvement & 4.96 & 1.12 & $.16^{*}$ & $-.18^{* * *}$ & -.03 & $.25^{* * *}$ & $.28^{* * * *}$ & $-.19^{* *}$ & .07 & & \\
\hline 9. Customer involvement & 5.07 & 1.12 & $.25^{* * *}$ & -.12 & .07 & $.36^{* * *}$ & $.17^{*}$ & $-.19^{* *}$ & $.13^{*}$ & $.55^{* * *}$ & & \\
\hline 10. Team size & 10.45 & 5.35 & .50 & $.36^{* * * *}$ & .06 & -.01 & $.17^{*}$ & .06 & .11 & .05 & .06 \\
\hline
\end{tabular}

${ }^{a} \mathrm{n}=168$

$* \mathrm{p}<.05$

$* * \mathrm{p}<.01$

$* * * \mathrm{p}<.001$

Table 1. Means, Standard Deviations, and Correlations ${ }^{a}$. 


\begin{tabular}{|c|c|c|c|c|}
\hline \multirow[b]{3}{*}{ Independent Variables } & \multicolumn{4}{|c|}{ New Product Quality } \\
\hline & \multicolumn{2}{|c|}{ Model 1} & \multicolumn{2}{|c|}{ Model 2} \\
\hline & $\hat{\mathbf{a}}$ & $\mathbf{t}$ & $\hat{\mathbf{a}}$ & $\mathbf{t}$ \\
\hline \multicolumn{5}{|l|}{ Control variable } \\
\hline Team size & 0.08 & 1.18 & 0.09 & 1.49 \\
\hline \multicolumn{5}{|l|}{ Direct effects } \\
\hline Functional diversity & -0.03 & -0.48 & -0.07 & -1.01 \\
\hline Tenure diversity & 0.08 & 1.30 & 0.07 & 1.24 \\
\hline Capability of & 0.39 & $5.48^{* * * *}$ & 0.66 & $2.15^{*}$ \\
\hline \multicolumn{5}{|l|}{ information integration } \\
\hline Speed-to-market pressure & -0.47 & -0.76 & -0.17 & $-2.19^{*}$ \\
\hline Product innovativeness & -0.38 & $-6.18^{* * * *}$ & -0.50 & $-2.04^{*}$ \\
\hline Quality orientation & 0.17 & $2.58^{* *}$ & 0.59 & $2.39^{* *}$ \\
\hline Supplier involvement & -0.03 & -0.38 & -0.02 & -0.25 \\
\hline Customer involvement & 0.03 & 0.38 & 0.01 & 0.15 \\
\hline \multicolumn{5}{|l|}{ Moderating effects } \\
\hline Capability of & & & 0.22 & $2.05^{*}$ \\
\hline \multicolumn{5}{|l|}{ information integration $x$} \\
\hline \multicolumn{5}{|l|}{ speed-to-market pressure } \\
\hline Capability of & & & 0.13 & 0.54 \\
\hline \multicolumn{5}{|l|}{ information integration $x$} \\
\hline \multicolumn{5}{|l|}{ product innovativeness } \\
\hline Quality orientation $\times$ & & & -0.78 & $-1.82^{\dagger}$ \\
\hline \multicolumn{5}{|l|}{ capability of } \\
\hline \multicolumn{5}{|l|}{ information integration } \\
\hline$R^{2}$ & 0.45 & & 0.47 & \\
\hline$\ddot{A} R^{2}$ & & & $0.02^{* * * *}$ & \\
\hline$F$ & $16.57^{* * * *}$ & & $13.48^{* * * *}$ & \\
\hline
\end{tabular}

$\dagger p<.10$

$* p<.05$

$* * p<.01$

$* * * p<.001$

Table 2. Results of Moderated Regression Analyses. 


\section{Direct Effects}

The results of testing hypotheses related to direct effects are shown in Table 2. Hypothesis 1 states that the more functionally diverse new product development teams are, the higher the new product quality will be. This hypothesis is not supported, in that the coefficient for the linear term $(\hat{a}=-0.07, t=-1.01, p=0.31)$ was not significant. Hypothesis 2 posits that the more tenure diverse new product development teams are, the higher the new product quality will be. The results did not support the linear relationship between tenure diversity and new product quality proposed in Hypothesis 2 . The Coefficient for the linear term $(\hat{a}=0.07, t=$ $1.24, p=0.22$ ) was not significant.

Consistent with expectations, the capability of information integration of a new product development team was positively related to new product quality $(\hat{a}=0.66, t=2.15, p<0.05)$; thus Hypothesis 3 is supported. As was expected, speed-to-market was negatively related to new product quality $(\hat{a}=-0.17, t=-2.19, p<0.05)$; thus Hypothesis 4 is also supported. To explore further if speed-to-market pressure below a moderate level has a stronger positive relationship to product quality than does speed-to-market beyond a moderate level, we dichotomized the speed-to-market pressure at its median. We then correlated product quality with speed-to-market pressure below a moderate level and beyond a moderate level. The results shows that speed-to-market pressure below a moderate level seems to have a stronger relationship to new product quality $(r=0.43, p<0.01)$ than does speed-to-market pressure below a moderate level $(r=0.24, p=0.07, \mathrm{~ns})$.

Referring to Hypothesis 5, product innovativeness was expected to reduce new product quality. Because coefficient for the linear term $(\hat{a}=-0.5, t=-2.04, p<0.05)$ was significant, this hypothesis is supported. Furthermore, it was hypothesized that quality orientation would be positively related to product quality. This prediction was also supported ( $\hat{a}=0.59, t=2.39$, $p<0.01)$.

The results did not support the linear relationship between supplier and customer involvement and product quality. Coefficients for both supplier $(\hat{a}=-0.02, t=-0.25, p$ $=0.81)$ and customer $(\hat{a}=0.01, t=0.15, p=0.88)$ involvement were not significant. Thus Hypothesis 7 and Hypothesis 8 were not supported.

\section{Moderating Effects}

The results of the moderated regression analysis are shown in Table 2. Consistent with Hypothesis 9, capability of information integration will reduce the negative effect of speedto-market pressure on new product quality. The interaction between speed-to-market pressure and capability of information integration was significant $(\hat{a}=0.22, t=2.05, p<0.05)$. Hypothesis 9 was supported.

Hypothesis 10 predicts that the negative effect of product innovativeness on new product quality will be mitigated by the capability of information integration of a new product development team. On the basis of the moderated regression analysis shown in Table 2, the interaction between capability of information integration and product innovativeness was not significant $(\hat{a}=0.13, t=0.54, p=0.59)$. Therefore, Hypothesis 10 is not supported.

It was hypothesized that quality orientation was expected to enhance the effect of capability of information integration on new product quality. The interaction between quality orientation and capability of information integration was weakly significant $(\hat{a}=-0.78, t=-1.82, p<$ 0.1). Thus, Hypothesis 11 was not supported. 
The covariate team size was found to have no significant effect on new product quality $(\hat{a}=$ $0.09, t=1.49, p=0.14)$.

\section{Discussion and Future Research Directions}

This study mainly tests how new product development teams' characteristics and organization contextual factors influence new product quality. The results show that new product quality is positively affected by the capability of information integration in the team and quality orientation in the firm, but negatively influenced by speed-to-market pressure and product innovativeness in the firm. Functional and tenure diversity have no effect on new product quality. The capability of information integration in a team can reduce the negative effect of speed-to-market pressure on new product quality.

There were six hypotheses that were not supported. First, functional diversity was found to have no relation to new product quality, but the capability of information integration in a cross-functional team did have a positive effect on quality. These findings could be interpreted that although functional diversity in product development teams offers direct access to expertise and the facilitation to product transfer, it is not sufficient to influence new product quality. On the contrary, the capability of information integration in a cross-functional team could develop a shared purpose and an effective team process among team members from different "thought-worlds". Thus, new product quality depends on how cross-functional teams integrate information and perspectives rather than their functional diversity.

Second, there was no effect of tenure diversity on new product quality. The absence of the main effect of tenure diversity seems to confirm the perspective by Katz (1982) that only at moderate levels of team tenure, team members are more likely to engage in both extensive internal and external communication and, therefore, to receive maximum benefit. Therefore, further research may be able to identify the extent to which the level of tenure diversity will influence new product quality most.

Third, no relationship was found between supplier involvement and new product quality. Although Clark and Fujimoto (1991) and Imai et al. (1985) noted that supplier involvement in product development could cut the complexity of the product design process, and improve the product concept, the effect of supplier involvement on new product quality seems to depend on different kinds of industries. Thus, which industry and what stage of development process will cause the effect of supplier involvement on new product quality will need to be further studied. We leave this for future research.

Fourth, there was no effect of customer involvement on new product quality. It is not clear why customer involvement did not affect new product quality as one would intuitively expect. Future research is needed to examine this. One possible explanation is that different products require different treatments, so that some products really need the customers' feedback to check and ensure whether the teams' product concept will fully satisfy the market needs, but others don't.

Fifth, no moderating effect of capability of information integration on the product innovativeness-quality relationship could be discovered. Future research may examine whether the negative effect of product innovativeness on new product quality is more likely to be found in more turbulent industries such as the information technology industry, and whether capability of information integration plays any role in reducing the negative effect of product innovativeness in such industries. It might also be interesting to test whether different levels of product innovativeness lead to differential effects on new product quality. 
Finally, a weak negative moderating effect of quality orientation on the capability information integration-quality relationship was detected. In the previous section, however, we postulated that there exists a positive moderating effect, expecting that quality orientation will be helpful to those cross-functional teams with high capability of information integration. Conversely, we did find a negative moderating effect which supports the findings of Sethi's research (2000). As Sethi explained in his paper, this reverse effect seems to be reasonable. Since team members in firms with quality orientation will be entrusted more to develop high-quality products, and the manufacturing equipment of the firms are also of better quality, then a team with a low capability of information integration is still able to develop a high-quality product. Thus, in a firm with quality orientation, the capability of information integration in new product development teams seem to play a less significant role in influencing new product quality. We leave this for future research to investigate how quality orientation in the firm affects the ability of product development teams to influence new product quality.

\section{Conclusions}

In conclusion, it seems useful to inform managers that the increased reliance on crossfunctional product development teams to develop high-quality products has not always led to the results as might be expected. We hope our findings and the model we have provided will assist managers in identifying the team characteristics and organization contextual factors needed to assist new product development teams to develop high-quality products. Since these factors can be directly manipulated by managers, they can create the effective conditions, specific to the industry characteristics they are engaged in, for new product development teams to develop high-quality products.

To be specific, we found that neither functional nor tenure diversity within the team was perceived to influence product quality. Rather than discard these notions however, management might want to play a bigger role in assignment of functions and tenure to teams. Tuckman and Jensen (1977) has shown that diverse teams outperform homogenous teams after team members learn to deal with performance inhibitors, additional factors such as more selectivity in functions and tenure assignments might prove productive. Control over these seemingly important factors might enhance the quality of the output.

While our research did not address the amount of team development in the new product development teams we investigated, the heterogeneity of team composition would suggest that factors such as; speed-to-market, product innovativeness, and quality orientation are targets for improvement through team training and development. Team development progresses through stages (Jackson, May \& Witney 1995). The speed and efficiency experienced through these stages would be enhanced through formal training programs based on new product development teams' specific needs.

It can be said from our research that new product development teams are well suited to current market dynamics, but management might want to consider a more proactive role in their formulation and development if they arte to reach their potential

\section{References}

Aaker, DA \& Jacobson, R (1994), 'The financial content of perceived quality', Journal of Marketing Research, vol. 31, no. 2, pp. 191-201.

Allison, PD (1978), 'Measures of inequality', American Sociological Review, vol. 43, no.3, pp. 865-880. 
Ancona, DG \& Caldwell, DF (1992), 'Demography and design: Predictors of new product team performance', Organization Science, vol. 3, no. 3, pp. 321-341.

Ancona, DG, Kochan, T, Scully, M, Maanen, JV \& Westney, DE (eds) (1996), Managing for the future, South-Western College, Cincinnati, Ohio.

Bantel, KA \& Jackson, SE (1989), 'Top management and innovations in banking: Does the composition of the top team make a difference', Strategic Management Journal, vol. 10, no. 1, pp 107-124.

Barczak, G \& Wilemon, D (1992), 'Successful new product team leaders', Industrial Marketing Management, vol. 21, no. 1, pp. 61-68.

Bonaccorsi, A \& Lipparini, A (1994), 'Strategic Partnerships in New Product Development: An Italian Case Study', Journal of Production Innovation Management, vol. 11, no. 2, pp. 134-145.

Booz, Allen \& Hamilton. (eds) (1982), Management of new products, Booz, Allen \& Hamilton, Chicago.

Bounds, G, Yorks, L, Adams, M \& Ranney, G (eds) (1994), Beyond total quality management, McGraw-Hill, New York.

Brown, SL \& Eisenhardt, KM (1995), 'Product development: Past research, present findings, and future directions', Academy of Management Review, vol. 20, no. 2, pp. 343-378.

Byrne, JA (1994), 'Remembering Deming, the godfather of quality', Business Week, January, pp. 44.

Calonius, E (1991), 'Smart moves by quality champs', Fortune, vol. 123, no. 12, pp. 24-28.

Chang, TJ, Hu, GG \& White, LP (2002), 'The effectiveness model of cross-functional project teams in Taiwan' in Proceedings of the 12th International Conference on Comparative Management, College of Management, National Sun Yat-sen University, Kaohsiung, Taiwan, R.O.C.

Clark, KB \& Fujimoto, T (1991), Product development performance, Harvard Business School Press, Boston.

Cooper, RG \& Kleinschmidt, EJ (1987), 'New Product: What separates winners from losers', Journal of Product Innovation Management, vol. 4, no. 3, pp. 169-184.

Curry, DJ (1985), 'Measuring price and quality competition', Journal of Marketing, vol. 49, no. 2, pp. 106-117.

Day, GS \& Wensley, R (1988), 'Assessing advantage: A framework for diagnosing competitive superiority', Journal of Marketing, vol. 52, no. 2, pp. 1-20.

Deshpande, R \& Zaltman, G (1982), 'Factors affecting the use of market information: A path analysis', Journal of Marketing Research, vol. 19, no. 1, pp. 14-31.

Eisenhardt, KM \& Tabrizi, BN (1995), 'Accelerating adaptive process: Product innovation in the global computer industry', Administrative Science Quarterly, vol.40, no. 1, pp. 84110 .

Fornell, C (1992), 'A national customer satisfaction barometer: The Swedish experience', Journal of Marketing, vol. 56, no. 1, pp. 6-21. 
Garvin, DA (1984), 'Product quality: An important strategic weapon', Business Week, MarchApril, pp. 40-43.

Garvin, DA (ed) (1988), Managing quality, The Free Press, New York.

Griffin, A \& Hauser, J (1996), 'Integration of R\&D and marketing: A review and analysis of the literature', Journal of Product Innovation Management, vol. 13, no. 3, pp. 191-215.

Gupta, AK, Raj, SP \& Wilemon, D (1986), 'A model for studying R\&D-marketing interface in the product development process', Journal of Marketing, vol. 50, no. 2, pp. 7-17.

Gupta, AK \& Wilemon, DL (1990), 'Accelerating the development of technology-based new product', California Management Review, vol. 32, no. 2, pp. 24-44.

Hackman, RJ \& Wageman, R (1995), 'Total quality management: Empirical, conceptual, and practical issues', Administrative Science Quarterly, vol. 40, no. 2, pp. 309-342.

Hauser, JR \& Clausing, D (1988), 'The house of quality', Harvard Business Review, vol. 66, no. 3, pp. 309-319.

Iansiti, M (1993), 'Real-world R\&D: Jumping the product generation gap', Harvard Business Review, vol. 71, no. 3, pp. 138-147.

Imai, K, Ikujiro, N \& Takeuchi, H (1985), 'Managing the new product development process: How Japanese companies learn and unlearn' in The uneasy alliance: Managing the productivity-technology dilemma, eds. RH Hayes, KB Clark \& C Lorenz, Harvard Business School Press, Boston, pp. 307-373.

Imai, M (ed) (1986), Kaizen: The key to Japan's competitive success, Random House, New York.

Jackson, SE, May, KE \& Witney, K (1995), 'Understanding the dynamics of diversity in decision-making' in Team effectiveness and decision-making in organizations, eds. RA Guzzo, \& E Sales, Jossey Bass, San Francisco.

Jacob, R (1993), Beyond quality \& value. Fortune, vol. 128, no. 13, pp. 8-11.

Kahn, K (1996), 'Interdepartmental integration: A definition with implications for product development performance', Journal of Product Innovation management, vol. 13, no. 2, pp. 137-151.

Karau, SJ \& Kelly, JR (1992), 'The effects of time pressure and time abundance on group performance quality and interaction process', Journal of Experimental Social Psychology, vol. 28, no. 6, pp. 542-571.

Keller, RT (2001), 'Cross-functional project groups in research and new product development: Diversity, communications, job stress, and outcomes', Academy of Management Journal, vol. 44, no. 3, pp. 547-555.

Lutz, RA (1994), 'Implementing technological change with cross-functional teams', Research-Technology Management, vol. 37, no. 2, pp. 14-18.

Menon, A, Jaworski, BJ \& Kohli, AK (1997), 'Product quality: Impact of interdepartmental interactions', Journal of the Academy of Marketing Science, vol. 25, no. 3, pp. 187-200.

Morgan, NA \& Piercy, NF (1998), 'Interactions between marketing and quality in the SBU level: Influences and outcomes', Journal of the Academy of Marketing Science, vol. 26, no. 3, pp. 190-208. 
Olson, EM, Walker, OC \& Ruekert, RW (1995), 'Organizing for effective new product development: The moderating role of product innovativeness', Journal of Marketing, vol. 59, no. 1, pp. 48-62.

Pfeffer, J \& O'Reilly, C (1987), 'Hospital demography and turnover among nurses', Industrial Relations, vol. 26, no. 2, pp. 158-173.

Phillips, LW, Chang, DR \& Buzzell, RD (1983), 'Product quality, cost position and business performance: A test of some key hypotheses', Journal of Marketing, vol. 47, no. 2, pp. $26-42$.

Ruekert, RW \& Walker Jr. OC (1987), 'Marketing's interaction with other functional units: A conceptual framework and empirical evidence', Journal of Marketing, vol. 51, no. 1, pp. 1-19.

Sethi, R (2000), 'New product quality and product development teams', Journal of Marketing, vol. 64, no. 2, pp. 1-14.

Shetty, YK (1987), 'Product quality and competitive strategy', Business Horizons, vol. 30, no. 3, pp. 46-52.

Smith, PG \& Reinertsen, DG (eds) (1991), Developing products in half the time, Van Nostrand Reinhold, New York.

Song, MX, Souder, WE \& Dyer, B (1997), 'A causal model of the impact of skills, synergy, and design sensitivity on new product performance', Journal of Product Innovation Management, vol. 14, no. 2, pp. 5-18.

Souder, WE (ed) (1987), Managing new product innovations, Lexington Books, MA.

Takeuchi, H \& Nonaka, I (1986), 'The product development game', Harvard Business Review, vol, 64, no. 1, pp. 137-146.

Teachman, JD (1980), 'Analysis of population diversity', Sociological Methods and Research, vol. 8, no. 2, pp. 341-362.

Thamhain, HJ (1990), 'Managing technologically innovative team efforts toward new product success', Journal of Product Innovation Management, vol. 7, no. 1, pp. 5-18.

Tuckman, BW (1977), 'Stages of small group development revised', Group and Organizational Studies, vol. 2, no. 3, pp. 419-427.

Wheelwright, SC \& Clark, KB (eds) (1992), Revolutionizing product development. The Free Press, New York.

Zirger, BJ \& Maidique, M (1990), 'A model of new product development: An empirical test', Management Science, vol. 36, no. 7, pp. 867-883. 